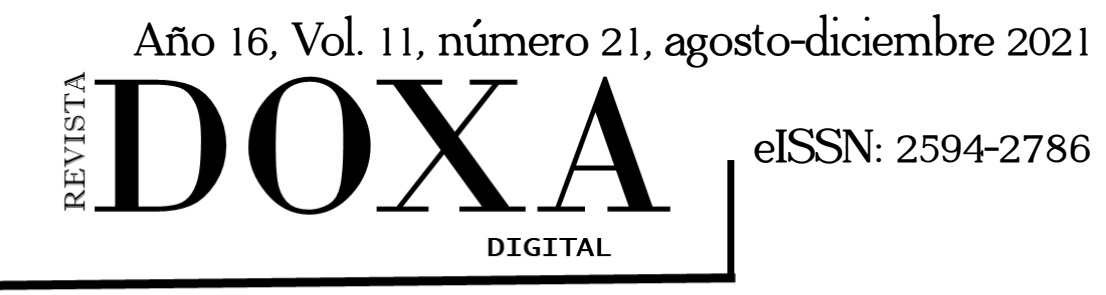

Sección: Ciencia Política

Recibido: Enero 2021

Aceptado: Junio 2021

DOI: $10.52191 /$ rdojs.2021.189

Pág.: 113-125

\title{
La emergencia de la COVID-19 y las respuestas del Estado
}

\section{The emergency of COVID-19 and the State's responses}

Eduardo Torres Alonso* y Andrea Samaniego Sánchez**

\section{RESUMEN}

Durante prácticamente todo año 2020, la humanidad vivió una modificación de sus formas y prácticas de convivencia. La pandemia de la COVID-19 obligó a las personas a recluirse en sus domicilios, interrumpiendo, por momentos, la mayoría de las actividades sociales. No obstante, las consecuencias de la enfermedad no sólo son médicas, sus efectos se han sentido también en las instituciones políticas y en las formas de organizar el poder. El artículo reflexiona sobre las medidas que establecieron los Estados para contener los contagios y los efectos de la pandemia en las libertades y la democracia .

PALABRAS CLAVE: Democracia, libertades, derechos, Estado, COVID-19

\begin{abstract}
During the entire year of 2020 practically, humanity experienced a modification of its forms and practices of coexistence. The COVID-19 pandemic forced people to confine themselves to their homes, interrupting, at times, most of their social activities. However, the consequences of the disease are not only medical; its effects have also affected in political institutions and in the ways of organizing power. The article provides a reflection about the measurements established by the States to suppress contagions and the effects of the pandemic on freedoms and democracy.
\end{abstract}

KEY WORDS: Democracy, freedoms, rights, State, COVID-19.

\footnotetext{
* Autor para correspondencia. Maestro en Administración Pública, Profesor de la Facultad de Ciencias Políticas y Sociales de la Universidad Nacional Autónoma de México (UNAM) y secretario técnico del Seminario Universitario de Estudios sobre Sociedad, Instituciones y Recursos de la UNAM. Contacto: etorres@unam.mx

** Doctora en Ciencias Políticas y Sociales. Profesora de la Facultad de Ciencias Políticas y Sociales de la Universidad Nacional Autónoma de México. Contacto: andrea.samaniego@politicas.unam.mx
} 
Año 16, Vol. 11, número 20, agosto-diciembre

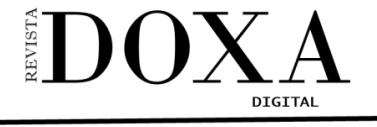

Sección: Ciencia Política

DOI: $10.52191 /$ rdojs.2021.189

Pág.: 113-125
Eduardo Torres Alonso y

Andrea Samaniego Sánchez

La emergencia del COVID-19.

\section{Introducción}

La emergencia de salud ocasionada por el virus SARS-CoV-2, que produce la enfermedad conocida como COVID-19, ha provocado un estado insólito de cuarenta global. Esta circunstancia hizo emerger un Leviatán sanitario que a la vez que estableció medidas para evitar la propagación de la enfermedad, particularmente, la reclusión domiciliaria instaló un sistema de vigilancia de las personas. Nunca como ahora la inmensa mayoría de la población mundial está sujeta a controles y seguimientos por parte de la autoridad (Sympa, 2020). A la vez, la emergencia de salud pública ha provocado un cuestionamiento severo de las políticas de ajuste estructural que han afectado, entre otros, los sistemas de salud de los países. Del Estado mínimo se ha pasado, en estos momentos, a la exaltación de la presencia del Estado como el gran protector de la ciudadanía.

Esta aparente protección se ha reflejado en medidas que han incluido el cierre de las fronteras como un recurso de reafirmación de la soberanía y del señalamiento del otro, generalmente extranjero, como el responsable de los contagios. No obstante, las migraciones, antes y durante la pandemia, reflejan conflictos, escasez y persecuciones. Los gobiernos enfrentan el reto mayúsculo de brindar condiciones temporales de apoyo a las personas migrantes hasta que la emergencia sanitaria concluya, puesto que su aglomeración representa un riesgo de contagio significativo. Es lamentable advertir no sólo entre las personas migrantes sino en la sociedad en general que la salud es un "privilegio de clase". El hacinamiento, la desnutrición, la necesidad de salir a trabajar o de huir de sus lugares de origen por las condiciones existentes ahí, son puertas de entrada para el virus que ha puesto de cabeza a las instituciones globales.

Además, aparece en el horizonte, así se con fragilidad, el retorno del Estado social ya que los gobiernos han destinado millones de dólares a los desempleados y a los servicios sanitarios. Las cifras varían, pero el objetivo es el mismo: no dejar a la población a su suerte. Veamos: el gobierno alemán anunció un paquete de medidas sanitarias y económicas por 156,000 millones de euros; en España, la cifra asciende a 200,000 millones de euros, y en Francia, las ayudas serán por 45,000 millones de euros y las garantías de préstamos por 300,000 millones (Sympa, 2020). Un nuevo gran pacto se ha puesto sobre la mesa. Un Plan Marshall para el siglo XXI.

Este trabajo persigue el objetivo de reflexionar sobre los distintos efectos que la pandemia ha tenido en la democracia, las libertades y las instituciones. Es claro que las consecuencias de la enfermedad no sólo se verán reflejadas en el ámbito sanitario, sino que otras dimensiones de la vida 
Año 16, Vol. 11, número 20, agosto-diciembre

DOXA
Sección: Ciencia Política

DOI: $10.52191 /$ rdojs.2021.189

Pág.: 113-125
Eduardo Torres Alonso y

Andrea Samaniego Sánchez

La emergencia del COVID-19.

social serán afectadas; incluso, los mecanismos de división de poderes y de integración de los cargos públicos, propios de las democracias, han resentido los efectos de la enfermedad, poniendo en riesgo la naturaleza democrática de algunos países.

La pandemia puede y debe ser analizada desde diferentes ángulos ya que en ella confluyen distintos elementos que van más allá de los propiamente médicos. El cambio que enfrentamos no es menor: las certezas y rutinas que habíamos dado por hechas durante este siglo se encuentran en duda. Nunca antes habíamos vivimos en estado de cuarentena global, y nunca pensamos que sería tan veloz la instalación de un Estado de excepción transitorio, un Leviatán sanitario, por la vía de los Estados nacionales.

\section{Igualdad y gobernabilidad}

En la época de la "Gran Pestilencia" (Keane, 2020), unos son más iguales que otros, los miedos hacen que los que tienen más recursos acaparen provisiones y medicamentos, dejando en la incertidumbre a los desposeídos. El confinamiento, como primera medida para evitar el contagio, es viable en aquellos lugares en donde existen condiciones mínimas de bienestar: el espacio domiciliario es adecuado, hay acceso a servicios públicos de calidad y se tiene una conexión a Internet. No lo es, por otro lado, en zonas económicamente deprimidas, en donde sus habitantes tienen que salir a trabajar para tener ingresos para comer. La brecha de desigualdades -que siempre ha estado ahí - se ha hecho más evidente y clara. No obstante, incluso en las capas medias de la sociedad, el confinamiento ha traído secuelas negativas, precisamente, porque nadie estaba preparado para transformar de forma abrupta las rutinas, en el mejor de los casos, o encontrarse de un día para otro en el desempleo por el cierre de negocios y empresas de escala diversa, entrando en una situación precaria al agotarse su fondo de ahorro, en caso de que éste existiera. A los gobiernos les preocupa no sólo la crisis sanitaria sino también la social y la política.

Los gobiernos están nerviosos en todas partes. Saben que sus poderes descansan en último término en el consentimiento de los gobernados.

$[\ldots]$

Como las democracias monitorizadas disfrutan de una cobertura mediática libre, son especialmente vulnerables a las historias que extienden temores sobre la aniquilación. Tucídides señaló en la Historia de la guerra del Peloponeso (431 a. C.) que la plaga de tifus que mató a casi una tercera parte de los ciudadanos de la Atenas democrática causó un caos político. Mientras la gente "moría como corderos", los 
Año 16, Vol. 11, número 20, agosto-diciembre

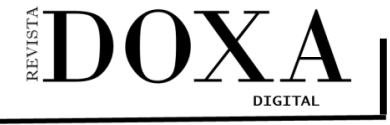

Sección: Ciencia Política

DOI: $10.52191 /$ rdojs.2021.189

Pág.: 113-125
Eduardo Torres Alonso y

Andrea Samaniego Sánchez

La emergencia del COVID-19.

rumores animaban a los supervivientes a vivir de forma temeraria, solo para sí mismos. La falta de respeto hacia la moral "tan sagrada como profana" floreció. Eso produjo una "mayor falta de ley" (Keane, 2020).

La democracia en este contexto enfrenta, con mayor incertidumbre, un enemigo serio: el populismo (Urbinati, 2020; Rosanvallon, 2020; Vallespín y Bascuñán, 2017; Müller, 2017), que ofrece soluciones rápidas, novedosas y efectivas a los problemas, aunque la democracia hace eso: soluciona problemas, busca innovar en la manera en que se intervienen aquéllos, trata que la respuesta beneficie a la mayor cantidad de personas, tenga un bajo costo y su duración sea prolongada, pero a diferencia de la inmediatez de las respuestas que pregonan los populistas, sean de derecha o de izquierda, la democracia tiene un ritmo distinto, más lento, ya que el diseño de una solución en clave democrática implica el diálogo, la concertación, el debate y, finalmente, el acuerdo (Bizberg, 2020). ¿Esto es un problema? En momentos de inquietud en donde la ciudadanía se siente amenaza, sí; pero, a la vez, no, en tanto que la deliberación democrática busca proteger los intereses de la ciudadanía resguardando sus derechos y libertades. En democracia, los ciudadanos podrán juzgar en las urnas el manejo que hicieron las autoridades de la crisis de salud, pero en los sistemas autoritarios esta posibilidad esta clausurada. Más aún: el disenso público no existe.

Las diferentes medidas que han tomado distintos gobiernos en el mundo para hacerle frente a la enfermedad han hecho que existan riesgos para el ejercicio de las libertades. De esta manera, la vigilancia del poder y de sus dictados viene a ser un requisito indispensable para que en el "día después", la democracia se mantenga como la forma de gobierno y no sea suplantada por gobernantes déspotas o autócratas. Muestra de ello son las formas interesadas y poco aseadas que Viktor Orbán y Narendra Modi, en Hungría e India, respectivamente, han utilizado la pandemia para arrogarse facultades, fracturando el pacto constitucional. La convivencia en la "nueva normalidad" debe estar fundada como sucedía antes de la pandemia: en instituciones con facultades establecidas, en donde el poder frene al poder y la ciudadanía puede tener la seguridad que sus libertades no están en riesgo (Keane, 2020). Las declaraciones de Estados de emergencia o de excepción, que se incrementaron conforme la enfermedad franqueaba las fronteras y contagiaba a más personas, no pueden ser medidas permanentes. Su naturaleza obedece a circunstancias temporal e incluso geográficamente establecidas.

Los sistemas constitucionales democráticos prevén que en situaciones excepcionales las facultades de decisión se concentren para hacer más ágiles y eficaces las respuestas del poder. Se admite la suspensión provisional de los procedimientos estándar para dar margen a modalidades tan extraordinarias como los fenómenos mismos a los que se hace frente. Esta es una forma dinámica de reacción que se como dictadura desde la república romana; en la actualidad, puede ser encuadrada como una forma efímera, regulada y contro- 
Año 16, Vol. 11, número 20, agosto-diciembre

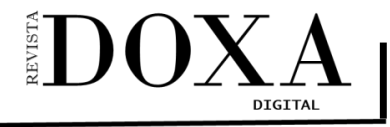

Sección: Ciencia Política

DOI: $10.52191 /$ rdojs.2021.189

Pág.: 113-125
Eduardo Torres Alonso y

Andrea Samaniego Sánchez

La emergencia del COVID-19..

lada de dictadura constitucional.

Los problemas comienzan cuando las medidas legales excepcionales se ejercen de manera arbitraria o cuando en lugar de aplicar las previsiones normativas se opta por decisiones improvisadas y ajenas al marco jurídico (Valadés, 2021, p. 26).

Siguiendo a De Sousa Santos (2020, p. 40), "[...] en el futuro no solo tendremos que distinguir entre Estado democrático y Estado de excepción, sino también entre Estado de excepción democrático y Estado de excepción antidemocrático." Los tiranos buscarán aprovecharse para reforzar su régimen de ausencia de libertades y de sometimiento ciudadano; por ello, los organismos multilaterales, la sociedad civil y la oposición política deben mantenerse como vigilantes del poder. Para nada pueden volverse normales las medidas que limitan derechos. La restricción de la movilidad y la supervisión de las calles con drones, policías o militares debe obedecer a la legítima preocupación de salvar vidas y no al interés de espiar a los opositores. La localización de las personas contagiadas y su seguimiento en tiempo real por medio de sus dispositivos electrónicos (teléfonos celulares o relojes inteligentes) a través del Global Positioning System es válido siempre que la autoridad garantice el tratamiento de la información privada, se informe con regularidad a la opinión pública las acciones que se toman, exista un panel de expertos independientes que supervise las decisiones gubernamentales, y se catalogue la información de los pacientes como sensible. De otro modo, el acopio y tratamiento de la información puede ser discrecional y tener fines de otra índole.

\section{Tecnología y libertades}

Además del personal sanitario, son informáticos y especialistas en bigdata quienes están haciendo frente a la pandemia. El virus ha sembrado el miedo en el ciudadano y éste, para protegerse, cedió más libertades al Estado y aceptó restricciones a sus derechos. Mantener la videovigilancia después de la emergencia es una tentación de muchos gobernantes.

[...] las tecnologías implementadas para la gestión de la pandemia pertenecen a dos clases: las que vigilan el cumplimiento de la cuarentena y las que asisten al sistema de "seguimiento y rastreo" característico de las campañas de control epidemiológico. En las primeras, la novedad no es la tecnología, sino la legitimidad del acto mismo, que se salta varios derechos civiles bajo el marco de excepcionalidad de la emergencia. Hong Kong usa las pulseras electrónicas de los arrestos domiciliarios para vigilar infectados; Taiwán tiene un sistema de localización para cercarlos con una "valla digital". En Polonia y la India, los infectados envían un selfi verificado por geoposicionamiento y reconocimiento facial. El peligro es no saber durante cuánto tiempo se extenderá el estado de emergencia, y hay países como Hungría e Israel que ya han alterado la legislación para extenderlo indefinidamente.

La segunda clase de tecnologías está diseñada para establecer todos los posibles contagios que 
haya podido hacer una persona infectada. Google y Apple ya han impuesto una infraestructura propia de rastreo de trazabilidad basada en Bluetooth que pronto estará en los móviles de casi todo el planeta. Los Gobiernos, empresas e instituciones diseñarán sus apps sobre ella.

La tecnología de rastreo solo está justificada como complemento a protocolos apropiados de diagnóstico, estrictamente temporales y activados por el resultado positivo de un test. Sin el acceso a sistemas de diagnóstico fiable, que no generen falsos resultados, son solo sistemas de control de la población, que podría verse obligada a aceptarlos voluntariamente para volver al puesto de trabajo o coger un avión. A la pérdida de autonomía y de privacidad se suma el peligro de discriminación de colectivos empobrecidos y racializados que carecen de espacios de distanciamiento o se ven obligados a seguir trabajando en lugares de alto riesgo, como fábricas textiles, almacenes de distribución o empacadoras de carne (Peirano, 2020).

El uso de la tecnología pareciera estar modelando el comportamiento social; por ejemplo, China ha introducido un sistema de puntaje social -establecido antes de la pandemia- que permite una evaluación profunda de los ciudadanos: si alguien se pasa un semáforo, por ejemplo, pierde puntos y, en función del puntaje, podría ser objeto de sanciones ${ }^{1}$. El panóptico digital ha dejado de ser una teoría para convertirse en una realidad. Ahora bien, ¿puede decirse que los sistemas políticos cerrados, autoritarios, han enfrentado de mejor medida la pandemia? No es una pregunta de fácil solución. Es cierto que en dichas sociedades la disciplina social es mayor por razones culturales y filosóficas diría Han, pero en las sociedades abiertas, las democráticas, se ha registrado una menor letalidad puesto que existe mayor circulación de información, según The Economist.

Los cambios tecnológicos vinculados al trabajo, la diversión, el consumo y la educación que se ha presenciado en estos meses se venían dando con antelación, pero la reclusión los aceleró. Las diversas plataformas de entrega de productos, de televisión bajo demanda y el aprendizaje remoto han incrementado sustancialmente su valor en el mercado y, a la par, han obtenido mayores datos de ciudadanos-clientes. Aquí hay un nuevo elemento que los gobiernos deben considerar: la regulación del uso de los datos personales que hacen los particulares. La privacidad es una condición de la democracia contemporánea.

[...] los regímenes democráticos se caracterizan por establecer mecanismos que, por una parte, garanticen la privacidad individual y colectiva y, por la otra, limiten tanto la divulgación de la información personal como los sistemas de vigilancia y monitoreo. De ahí que la propia instauración de los regímenes democráticos mantenga como base de su estructura la salvaguarda de un sentido de privacidad que garan-

1 "El sistema de créditos sociales chino, que ya se encuentra en funcionamiento, otorga una puntuación a cada uno de sus ciudadanos en función de sus hábitos cívicos, su estilo de vida, las páginas web por las que navega, de lo que compra en internet y de otras variables como sus infracciones de tráfico. Una puntuación que marca la posición de los ciudadanos en la escala social del país de modo que, aquellos con un crédito alto, tendrán derecho a un trato preferente por parte de la Administración. [...] Aquellos con una puntuación baja, los que "rompen la confianza", se están enfrentando a represalias como la imposibilidad de acceder a determinados puestos de trabajo, la prohibición de comprar billetes de tren o avión, de alojarse en los mejores hoteles, de que sus hijos vayan a un buen colegio o, incluso, que el estado les quite a sus mascotas. Todo eso además de ser incluidos en listas negras públicas de malos ciudadanos" (Ollero, 2018). 
tice estos espacios de libertad de la persona para su realización plena y la construcción y manifestación individual o colectiva de su autonomía. Ello permite, por una parte, garantizar la existencia de ciertos ámbitos de exclusión de interferencias ajenas, incluyendo al propio Estado y, por la otra, otorgar a las personas la facultad de controlar la información que les concierne, con la finalidad de autodeterminarse frente al resto de la sociedad (Maqueo Ramírez y Barzizza Vignau, 2020, pp. 32-33).

Si esta fuera una preocupación adicional, otro tema se vincula a la seguridad informática de instalaciones estratégicas. Los ciberataques a instituciones oficiales han ocurrido y los hackers han "secuestrado" las redes de cómputo y solicitado la entrega de dinero para devolverlas. Los hospitales están en riesgo de sufrir este tipo de ataques, pero algunos grupos dedicados a estas actividades han señalado que la infraestructura hospitalaria no será objeto de secuestros y que si sus sistemas llegarán a ser encriptados será un error, devolviendo su autonomía de manera inmediata y gratuita (Peirano, 2020).

Los retos y los problemas que saltan a la vista en medio de la pandemia rebasan la capacidad de los gobiernos, incluso, por supuesto, a los democráticos que han solicitado salvoconductos a sus ciudadanos para ir de compras a la farmacia o al supermercado y han autorizado a las instituciones de seguridad civiles y militares, la imposición de multas o la detención de quienes infrinjan las nuevas normas de convivencia y confinamiento (Bizberg, 2020) ${ }^{2}$.

La emergencia actual y sus consecuencias no podrán ser solucionadas si no ocurre la modificación de las relaciones Norte-Sur en el marco del multilateralismo democrático. Es evidente que la amenaza a la continuidad de la vida tal y como se conocía antes de la presencia de la COVID-19 exige una respuesta integral que vaya más allá de lo propiamente inmediato. Se requiere que la agenda incluya los aspectos ambiental, social y económico. La pandemia ha puesto de relieve que

2 "La gran mayoría de los países del mundo llevan varias décadas debilitando de forma consciente e inconsciente sus instituciones públicas. Los mecanismos para ello comprenden un amplio espectro de estrategias. Destacamos aquí las que son más relevantes: Primero, la descapitalización de las administraciones públicas mediante lógicas de neoclientelismo de carácter político y la inhibición política ante la necesidad de renovar sus arquitecturas organizativas y sus modelos de gestión de recursos humanos. El resultado es que cada vez hay menos alicientes para los expertos en distintas materias y para los buenos gestores prestar sus servicios en la Administración. El talento ya no tiene interés en trabajar en las instituciones públicas y en el caso marginal de aquellos que optan por acceder a ellas, gracias a sus elevados valores públicos, quedan arrinconados y anestesiados por una deficiente cultura política excesivamente intrusiva y por unas lógicas administrativas caóticas y caducas que adormecen al más entusiasta. Segundo, la falta de un buen liderazgo político de las instituciones públicas que fomentan un mal o pésimo gobierno frente a la necesidad de un buen gobierno. [...] Tercero, la política y los partidos políticos tradicionales, encorsetados por los elementos de los dos puntos anteriores, han sido incapaces de dar respuesta a los retos sociales y económicos más acuciantes. [...] Cuarto, los procesos de privatización de los denominados servicios universales de interés general (energía, telecomunicaciones, transportes, pensiones en muchos países, gestión del agua potable, etc.) han sido un fracaso en buena parte de los casos. La contrapartida pública a este proceso debería haber sido una solvente regulación pública de estos servicios, ingrediente que solo se ha alcanzado a nivel formal pero no a nivel material. Quinto, el mercado cada vez está más presente en la gestión del bien común y del interés general. Ha ganado protagonismo por el espacio que han dejado las instituciones públicas cada vez más impotentes y desvencijadas y han ganado impulso por las revoluciones tecnológicas que han liderado (2.0 y, a partir de ahora, 4.0 de la mano de la inteligencia artificial y la robótica). [...] El resultado de todos estos vectores, ha generado una gran erosión del Estado como actor que es capaz de proveer bienestar a la ciudadanía y su 
Año 16, Vol. 11, número 20, agosto-diciembre

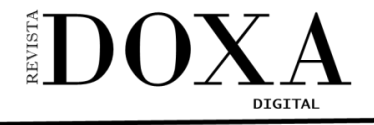

Sección: Ciencia Política

DOI: 10.52191/rdojs.2021.189

Pág.: 113-125
Eduardo Torres Alonso y

Andrea Samaniego Sánchez

La emergencia del COVID-19.

la solidaridad es un elemento de la mayor relevancia para la solución de los problemas de este tipo que no respeta las fronteras políticas. En el "día después" debe generarse un gran consenso sobre el futuro.

\section{Liderazgo y elecciones}

El liderazgo político ha sido una característica en este tiempo de pandemia. Este liderazgo puede ser clasificado en dos grandes tipos, uno de tipo racional y otro de naturaleza carismática. Es inevitable no traer a la mente la amplia discusión que Max Weber ofrece en Economía y sociedad al respecto. En efecto, ambos tipos de liderazgo buscan lo mismo: la supervivencia y continuidad de sus sociedades, pero lo hacen por medios diferentes. Mientras el liderazgo racional atiende las recomendaciones científicas, los líderes carismáticos exaltan su propia figura y apelan a sentimientos religiosos. Ellos buscan una explicación y solución propia de las sociedades tradicionales, mientras que los líderes del primer tipo están en el ámbito de la "ética de la responsabilidad" (Zabludovsky, 2020). En casi todo el mundo, las autoridades, incluidas aquellas electas en jornadas electorales pacíficas y competitivas, rechazan la autocrítica y no reconocen los errores de la estrategia para contener de la pandemia. Por supuesto, en las sociedades abiertas, el cuestionamiento social es permanente y no hay peligro por disentir, mientras que en los países subdesarrollados con gobiernos más próximos a los liderazgos carismáticos el cuestionamiento no tiene eco y se persigue, encarcela o desaparece a los críticos.

Un tema más que ha sido "tocado" por la pandemia es la renovación de las autoridades. Muchas campañas y elecciones han sido suspendidas o aplazadas. La COVID-19 parece que está decidiendo el reloj electoral del mundo. Con todo, las autoridades electorales nacionales y las agencias de asistencia en esta materia señalan que la circunstancia representa un desafío organizacional en la medida que supondrá que los organizadores de las elecciones diseñen estrategias para que la ciudadanía que vaya a votar lo haga con el menor riesgo posible y para que los funcionarios electorales cumplan con su tarea con una baja probabilidad de contagio. Una solución a esta coyuntura es la utilización de la tecnología para emitir el sufragio; no obstante, persiste el temor que los sistemas de votación sean alterados desvirtuando el resultado. Lo cierto es que ya sea que el voto se pueda emitir por Internet o sea enviado por correo postal, la pandemia hará que el voto in situ 
Año 16, Vol. 11, número 20, agosto-diciembre

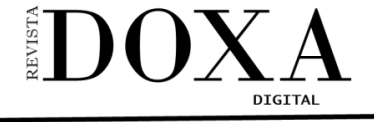

Sección: Ciencia Política

DOI: $10.52191 /$ rdojs.2021.189

Pág.: 113-125
Eduardo Torres Alonso y

Andrea Samaniego Sánchez

La emergencia del COVID-19.

sea replanteado. Finalmente, la abstención es algo que no debe dejarse pasar. Si la ciudadanía no se siente segura para acudir al punto de votación se quedará en casa aumentado el porcentaje de abstención y dejando en manos de una minoría la decisión de quiénes serán las nuevas autoridades (Gutiérrez-Rubí, 2020). La democracia se legitima con la participación y si ésta es desdeñada por los ciudadanos que no perciben beneficios en su vida cotidiana, se erosiona.

De acuerdo con el Instituto Internacional para la Democracia y la Asistencia Electoral (IDEA Internacional), en su informe "Panorama global del impacto del Covid-19 en las elecciones para el período 21 de febrero al 27 de septiembre de 2020", al menos 71 países y territorios decidieron posponer las elecciones nacionales y subnacionales por la pandemia. De ellos, al menos 22 corresponden a elecciones nacionales o referéndums. Más de sesenta países y territorios celebraron elecciones nacionales o subnacionales según lo establecieron en su calendario original, a pesar de las preocupaciones relacionadas con la COVID-19, de las cuales al menos 49 países han celebrado elecciones nacionales o referéndums, y al menos, 30 países y territorios han celebrado elecciones que inicialmente se pospusieron debido a preocupaciones vinculadas con la COVID-19 (IDEA Internacional, 2020). Esta celebración de las elecciones mantiene la legalidad; es decir, se efectuaron conforme en lo dispuesto en la ley, pero las circunstancias en las que se desarrollaron podrían socavar su integridad democrática. "[...] unas elecciones con pocos funcionarios, recintos cerrados, muy baja participación y sin apenas observación independiente pueden plantear un riesgo tan grande como las que se retrasan de forma indefinida" (Fundación Koffi Annan, 2020).

En los lugares en donde la votación fue presencial, la ciudadanía debió usar mascarillas y protección ocular; en la medida de lo posible, se separaron las urnas y las casillas; se instalaron protecciones de plástico para resguardar la salud de los funcionarios de las casillas; se desinfectaron constantemente los espacios de votación, en fin, se colocaron puntos con solución hidroalcohólica para desinfectarse las manos. Se dispusieron de todas las recomendaciones sanitarias que la evidencia científica sugería en ese momento (Libertad y Desarrollo, 2020). ¿Están en colisión las medidas gubernamentales que procuran el derecho a la vida como las que buscan la participación ciudadana en la integración del poder público? Es un falso debate porque, en principio, las autoridades deben dejar su puesto cuando termine su periodo constitucional no pudiendo extender su mandato -las constituciones establecen qué ocurre cuando habiendo terminado un periodo de gobierno no se han convocado a elecciones- y el derecho a la vida o a la salud no se pone en riesgo o al menos éste es mínimo si se implementan mecanismos remotos de votación, que no sean sustitutos de la votación presencial, o se genera una estrategia para la concurrencia ordenada a las urnas to- 
Año 16, Vol. 11, número 20, agosto-diciembre

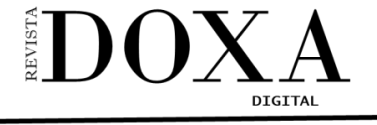

Sección: Ciencia Política

DOI: $10.52191 /$ rdojs.2021.189

Pág.: 113-125
Eduardo Torres Alonso y

Andrea Samaniego Sánchez

La emergencia del COVID-19.

mando las medidas de prevención necesarias.

El riesgo de enfermarse existe, por ello, a la población vulnerable se le debe de dar facilidades para votar. Las elecciones tienen que mantener su naturaleza: ser la manifestación libre expresión de la voluntad popular manifestada en el voto, no debiendo volverse en fuentes de contagio y, a la postre, de ingobernabilidad por las repercusiones sociales que eso conlleva.

\section{Movilización e impasse}

La suspensión de elecciones, la prolongación de mandatos, la restricción arbitraria de libertades, el establecimiento de medidas que poco o nada tienen que ver con el combate a la pandemia, hacen pensar, más bien, que la democracia, como se ha dicho en este documento, enfrenta un nuevo peligro. Ciertamente, la democracia como organización del poder, en donde se reconoce que los que ganan no lo harán siempre y los que pierden están en condiciones de triunfar en el futuro, ha estado bajo asedio por aquellos que no toleran la diversidad, pugnan por el pensamiento único y añoran épocas de un comportamiento homogéno. No obstante, en medio de la emergencia de salud pública la defensa de las instituciones democráticas y de sus valores en más difícil. La movilización presencial supone riesgos y el activismo digital muestra sus límites (Fundación Koffi Annan, 2020).

Más aún, la suspensión de la actividad legislativa, no sólo en la tarea de elaboración y reforma del marco jurídico, sino en la relevante labor de supervisar el actuar del poder Ejecutivo, en particular, ha hecho que los titulares de éste se arroguen facultades, legislen y gobiernen con decretos e incluso se vuelvan jueces. En muchos países las labores jurisdiccionales -que, entre otras cosas, incluyen la revisión de la constitucionalidad de las decisiones de los gobernantes- tanto de las cortes supremas como de tribunales menores han sido suspendidas. Los legisladores y los jueces, como los partidos políticos, en un primer momento, se retrajeron y cedieron su espacio al poder Ejecutivo. Sólo los integrantes del Ejecutivo elaboraron diagnósticos y propuestas de solución -muchas veces improvisados-, gradualmente los poderes públicos y los partidos han empezado a trabajar con la ayuda de la tecnología, lo que ha hecho que exista crítica y cuestionamiento a las medidas adoptadas, pero también que haya nuevas propuestas de solución y, por supuesto, se revise la constitucionalidad de las medidas, ratificándolas o revocándolas.

De manera afortunada para la salud de la democracia, los poderes Legislativo y Judicial han ido modificando sus reglamentos para estar en condiciones de sesionar con el auxilio de la tecnología. Es en tiempos excepcionales cuando los legisladores y los jueces se necesitan más para poner un freno a los excesos del Ejecutivo y revisar la constitucionalidad de sus actos. La continuidad de 
Año 16, Vol. 11, número 20, agosto-diciembre

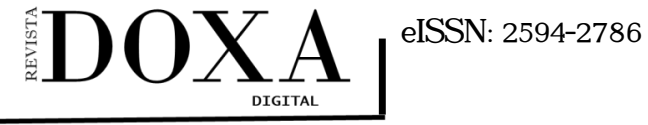

Sección: Ciencia Política

DOI: $10.52191 /$ rdojs.2021.189

Pág.: 113-125
Eduardo Torres Alonso y

Andrea Samaniego Sánchez

La emergencia del COVID-19.

todos los poderes no es opcional, por ello la utilización de mecanismos alternativos y complementarios con ayuda de la tecnología para el trabajo de las cámaras y la judicatura es imprescindible. Además, en materia jurídica, con las medidas de confinamiento se han afectado los plazos procesales se han visto afectados.

La fortaleza del Estado de derecho se demuestra en los momentos de crisis. Pensar que los derechos civiles son para cuando nos los podemos permitir es sencillamente no creer en los derechos civiles. $\mathrm{Si}$ en algún momento necesitamos que funcionen los mecanismos de control de las fuerzas de seguridad es cuando les otorgamos poderes extraordinarios. Y con frecuencia las pérdidas en libertades no son transitorias, sino que dejan secuelas en las instituciones y la cultura política de un país (Renduelles, 2020).

Con los Estados de excepción sufren los derechos humanos (Torres Alonso, 2020). Es cierto, dicha excepcionalidad es reconocida por los mismos instrumentos en materia de derechos humanos pero esas restricciones de las libertades y de los derechos deben ser claramente transitorias y en términos puntuales sólo para proteger la vida y la salud. El miedo no puede ganarle a la confianza, tanto en las personas como en las leyes y en las instituciones, ya que, si así ocurre, aparecen sujetos que desdeñarán las libertades, privilegiarán un sistema de vigilancia y espionaje permanente, y señalarán “chivos expiatorios” (Editorial, 2020).

\section{Aproximaciones finales}

Aunque el futuro es una conjetura, lo cierto es que el confinamiento estricto será levantado gradualmente y poco a poco se retomarán las actividades que implicará una reconstrucción de los vínculos sociales, económicos y familiares dañados por la pandemia. Las instituciones, gestoras del conflicto, deberán retornar a la normalidad democrática haciendo que pierdan vigencia los decretos de los estados de excepción y volviendo las facultades a cada poder, desconcentrándolas, y levantando las restricciones a las libertades. El peligro en sí no radica en la entrada en vigor de estados de excepción o de emergencia cuando todos los poderes trabajan con normalidad, el riesgo está cuando se normaliza dicho estado y los poderes públicos, a excepción del Ejecutivo, no se encuentran en operación.

De las grandes declaraciones políticas se debe pasar a la operación burocrática; es decir, al funcionamiento de las tuercas, tornillos y engranes de la gran maquinaria de la administración pública que haga posible una recomposición de lo público y un nuevo pacto en donde el Estado asuma su rol -otrora central- en la dirección social sin que ello signifique un estatismo abrazador. Por otro lado, el "Gran Hermano" que apareció con la vigilancia tecnológica debe ser restringido. La policía cibernética que a todos y a todo vigila en aras de la salud pública tiene que volver a su tarea, 
Año 16, Vol. 11, número 20, agosto-diciembre

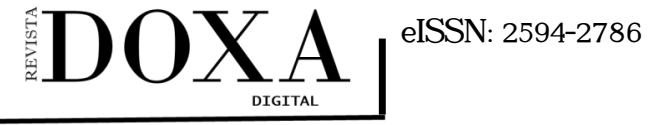

Sección: Ciencia Política

DOI: $10.52191 /$ rdojs.2021.189

Pág.: 113-125
Eduardo Torres Alonso y

Andrea Samaniego Sánchez

La emergencia del COVID-19.

y cuando haya oportunidad, los gobiernos con la participación de la sociedad, deben revisar el actuar de las policías tecnológicas durante el confinamiento y, de ser el caso, sancionar los abusos a los derechos humanos.

Se ha constatado que lo virtual y lo tecnológico no son una dimensión distinta a la humana. Si la sociedad pudo continuar -no sin dificultades, claro- fue gracias a la Internet y a las computadoras, teléfonos y tabletas. Por ello, una discusión fundamental en la "nueva realidad", oxímoron (Álvarez-Arana y Velázquez Toledo, 2020, p.212) interiorizado en el lenguaje, será la de hacer efectivo el derecho al olvido en la red y el derecho a la conexión. El primero para resuguardar el honor y los datos personales de una persona, y el otro para disminuir la brecha digital y las desigualdades que de ella se dervan. Contar con Internet es causa y consecuencia de una sociedad estratificada y construida en claves de desiguadad y exclusión. Se requiere un Estado más fuerte y más social que haga frente a los miedos del Estado hobbesiano, brinde certidumbre a la población y encare los costos de tomar decisiones.

Frente a una amenaza del tamaño de la COVID-19 las democracias actuaron mejor frente a los gobiernos autoritarios, aunque éstos lo hicieron más rápido. Esto es interesante en la medida en que el miedo se diseminaba, se exigían respuestas inmediatas. No obstante, a pesar de ese retardo, las respuestas de las democracias fueron más eficientes (Samaniego Sánchez y Torres Alonso, 2020) ya que, al existir libertades y elecciones, los gobernantes no pueden fallar. Los liderazgos populistas demostraron que sus instituciones son débiles frente a problemas de esta envergadura.

\section{Referencias}

Álvarez-Arana, S. y Velázquez Toledo, G. (2020). La Montaña mágica y la COVID-19. La literatura siempre. Espacio I+D, Innovación más Desarrollo, 9(25), especial, 208-222. https://doi.org/10.31644/IMASD.25.2020.a12

Bizberg, I. (2020, 31 de marzo). Pensar más allá de la pandemia. El País. https://elpais.com/elpais/2020/03/31/ opinion/1585610408_637589.html

Editorial (2020, 28 de marzo). Primer plazo. El País. https://elpais.com/elpais/2020/03/28/ opinion/1585410373_464612.html

Fundación Kofi Annan (2020, 21 de mayo). La democracia no puede convertirse en víctima silenciosa de la pandemia de coronavirus. El País. https://elpais.com/elpais/2020/05/19/planeta_futuro/1589894681_504573.html

Gutiérrez-Rubí, Antoni (2020, 20 de marzo). Elecciones en tiempos de coronavirus. El País. https://elpais.com/ elpais/2020/03/20/opinion/1584715049_536587.html

IDEA Internacional (2020). Panorama global del impacto del COVID-19 en las elecciones. https://www.idea.int/es/news- 
Año 16, Vol. 11, número 20, agosto-diciembre

DOXA
Sección: Ciencia Política

DOI: 10.52191/rdojs.2021.189

Pág.: 113-125
Eduardo Torres Alonso y

Andrea Samaniego Sánchez

La emergencia del COVID-19..

media/multimedia-reports/panorama-global-del-impacto-del-covid-19-en-las-elecciones

Keane, J. (2020, mayo). La democracia y la gran pestilencia. Letras Libres. https://www.letraslibres.com/espana-mexico/ revista/la-democracia-y-la-gran-pestilencia

Han, B. (2020, 22 de marzo). La emergencia viral y el mundo de mañana. El País. https://elpais.com/ideas/2020-03-21/ la-emergencia-viral-y-el-mundo-de-manana-byung-chul-han-el-filosofo-surcoreano-que-piensa-desde-berlin.html

Libertad y Desarrollo (2020, 26 de junio). Elecciones en pandemia: lo que hizo el mundo y el déficit de Chile. Temas Públicos, (1453-1), 1-7. https://archivos.lyd.org/lyd/TemasPublicos/TP\%201453\%20PROCESOS\% 20ELECTORALES.pdf

Maqueo Ramírez, M. S. y Barzizza Vignau, A. (2020). Democracia, privacidad y protección de datos personales. México: Instituto Nacional Electoral.

Müller, J-W. (2017). ¿Qué es el populismo? México: Grano de Sal.

Ollero, D. J. (2018, 31 de octubre). Comunismo por puntos: China activa una tecnología para medir el "valor social" de cada ciudadano. El Mundo. https://www.elmundo.es/tecnologia/2018/10/31/5bd8c1bfe2704e526f8b4578.html

Peirano, M. (2020, 30 de mayo). Privacidad: el riesgo totalitario. El País Semanal. https://elpais.com/elpais/2020/05/26/ eps/1590509740_451730.html

Ramió Matas, C. (2020). Coronavirus, modelos de Estado, toma de decisiones y la transformación de la gestión pública. GIGAPP Estudios / Working Papers, 7(182), 489-512.

Renduelles, C. (2020, 28 de marzo). La tormenta perfecta de autoritarismo. El País. https://elpais.com/ elpais/2020/03/27/opinion/1585301613_468266.html

Rosanvallon, P. (2020). El siglo del populismo. España: Galaxia Gutenberg.

Samaniego Sánchez, A. y Torres Alonso, E. (2020). Entre las libertades y la salud pública. La respuesta del gobienro mexicano ante la COVID-19. Espacio I+D, Innovación más Desarrollo, 9(25), especial, 118-128. https:// doi.org/10.31644/IMASD.25.2020.a07

Sousa Santos, Boaventura de (2020). La cruel pedagogía del virus. Consejo Latinoamericano de Ciencias Sociales. http://209.177.156.169/libreria_cm/archivos/La-cruel-pedagogia-del-virus.pdf

Svampa, M. (2020, abril). Reflexiones para un mundo post-coronavirus. Nueva Sociedad. https://nuso.org/articulo/ reflexiones-para-un-mundo-post-coronavirus/

Torres Alonso, E. (2020). Derechos fundamentales y COVID-19. Algunas reflexiones sobre la primera emergencia sanitaria global del siglo XXI. Cuaderno Jurídico y Político, VI(15), 27-41.

Urbinati, N. (2020). Yo, el pueblo. Cómo el populismo transforma la democracia. México: Instituto Nacional ElectoralGrano de Sal.

Valadés, D. (2021). Constitucionalismo crítico. Ideas para la transición constitucional en la era post Covid-19. México: Siglo XXI Editores.

Vallespín, F. y Bascuñán, Máriam M. (2017). Populismos. España: Alianza Editorial.

Zabludovsky, G. (2020, junio). Max Weber y la política en un mundo desencantado. Letras Libres. https:// www.letraslibres.com/mexico/historia/max-weber-y-la-politica-en-un-mundo-desencantado 